\title{
Digital Transformation Challenges in the Manufacturing Industry
}

\author{
Yasser Omar Abdallah a,c,1, Essam Shehab ${ }^{\mathrm{b}}$, Ahmed Al-Ashaab ${ }^{\text {a }}$ \\ a Manufacturing Department, School of Aerospace, Transport \& Manufacturing, \\ Cranfield University, Cranfield, Bedford, UK \\ ${ }^{b}$ Mechanical and Aerospace Engineering Department, School of Engineering and \\ Digital Sciences, Nazarbayev University, Nur-Sultan, Kazakhstan \\ essam.shehab@nu.edu.kz,https://nu.edu.kz/faculty/essam-shehab \\ ${ }^{c}$ Business Administration Department, Faculty of Commerce, Mansoura University, \\ Mansoura, Egypt
}

\begin{abstract}
Digital Transformation becomes an essential strategy for organisations in this new digital arena, specifically after the COVID-19 pandemic and its unprecedented effects on the whole world and the manufacturing sector. In this new digital era, consumers became more expert and more engaging in the products using new technologies. At the same time, companies began to adopt digital transformation strategies in their manufacturing processes to become more agile and give the most value to their customers in fierce competition. This paper aims to identify and model the main challenges that face the digital transformation process in the manufacturing industry.. The main challenges were categorized to four main areas: skills, adoption of new technologies, change management practices, and innovation initiatives. By identifying these challenges, in a new and incremental way, manufacturing organisations will be able to adopt digital transformation processes efficiently and effectively in a proper manner.
\end{abstract}

Keywords: Digital Transformation, Challenges, Manufacturing, Digitalisation

\section{Introduction}

Although the concept of Digital Transformation has been discussed for years, there is a lack of definition of it or what it may combine in the fundamental level. Especially in the manufacturing industry that faces many fast-paced technological advancements that change the entire shape of their business models ${ }^{1}$.

Digital Transformation strategy gives the organisation a new competitive advantage to cope with the latest digital technologies and make the most use. No doubt that concepts like Industry 4.0, Internet of Things (IoT), Cloud Computing, and many other new technologies can change the way of doing business ${ }^{2}$. With the fast pacing of technology development, business processes also are needed to cope with this rapid change, especially in developing countries that lack research in this field. By comparing traditional and digital organisations, later organisations can also grow their business

\footnotetext{
${ }^{1}$ Corresponding author, Manufacturing Department, School of Aerospace, Transport \& Manufacturing, Cranfield University, Cranfield, Bedford, UK Yasser.Abdallah@cranfield.ac.uk, https://www.cranfield.ac.uk/ people/yasser-abdallah-24604662
} 
more rapidly due to their high degree of flexibility to consumer needs and the adoption of fast-paced new technologies.

However, this transformation process is faced with many challenges and constraints in the small and medium enterprises (SMEs) only and on the large corporations. These challenges may differ from industry to industry.

Moreover, the degree of the same problems may also change over different sectors. This paper focuses on the manufacturing industry and the challenges facing the digital transformation process in $\mathrm{it}^{3}$.

\section{Digital Transformation Challenges}

Undoubtedly, most manufacturing companies are trying to adopt and operate digital transformation processes in their various departments because digital transformation is significant in terms of its scale. Moreover, it is impossible to escape the digital world if the company want to maintain its competition among others in the market. Many companies respond to this phenomenon through innovation and change initiatives such as design thinking workshops and hackathons. However, the impact of these initiatives is far beyond the expected results.

Digital transformation is a very dynamic and vast changing process. According to the KPMG CIO survey report in 2017, less than one to five digital transformation attempts succeeded. Moreover, only $18 \%$ of 70 companies surveyed in the report has a competent digital transformation process ${ }^{2}$. Digital transformation is about technology and creating a dynamic framework of all aspects of the organisation, including structure, workforce, and culture, to cope with these changes.

Significant challenges for Digital Transformation processes have been classified into four main categories: Skills Gap, The Adoption of New Technologies, Change Management Process, Innovation Policies and Procedures.

The proposed model of categorising the challenges of digital transformation is based on studying and analysing the last research papers in academia that relates to digital transformation challenges, specifically in the manufacturing industry ${ }^{2-5}$

As Figure (1) shows, these four challenges have many subsequent problems. In addition to that, they are interconnected and affect each other. For example, if the organisation enhances human resources' skills in the organisation, this will help quickly adopt new technologies and make change more efficient and effective.

\subsection{Skills Gap}

There is an apparent skills gap between the manufacturing organisations' digital skills and what they want to keep up with the digital pace. According to the SAP report in 2018 , there is, on average, between $20 \%-40 \%$ skills gap between what is needed and required. Moreover, in a recent study by Technical University Munich (TUM), 64\% of companies surveyed said they do not have the people with the skills necessary for digital transformation ${ }^{6}$. This percentage was on technologies like artificial intelligence, cloud computing, big data analytics, the internet of things, business networks.

Digital skills become necessary to implement digital transformation successfully, and these skills will increase in the upcoming years. Unfortunately, employers do not provide sufficient resources to train their employees. As more technologies developed and evolved in the manufacturing sector, employees need more training and capacity building programs to acquire the necessary skills to cope with this technologies ${ }^{7}$. 


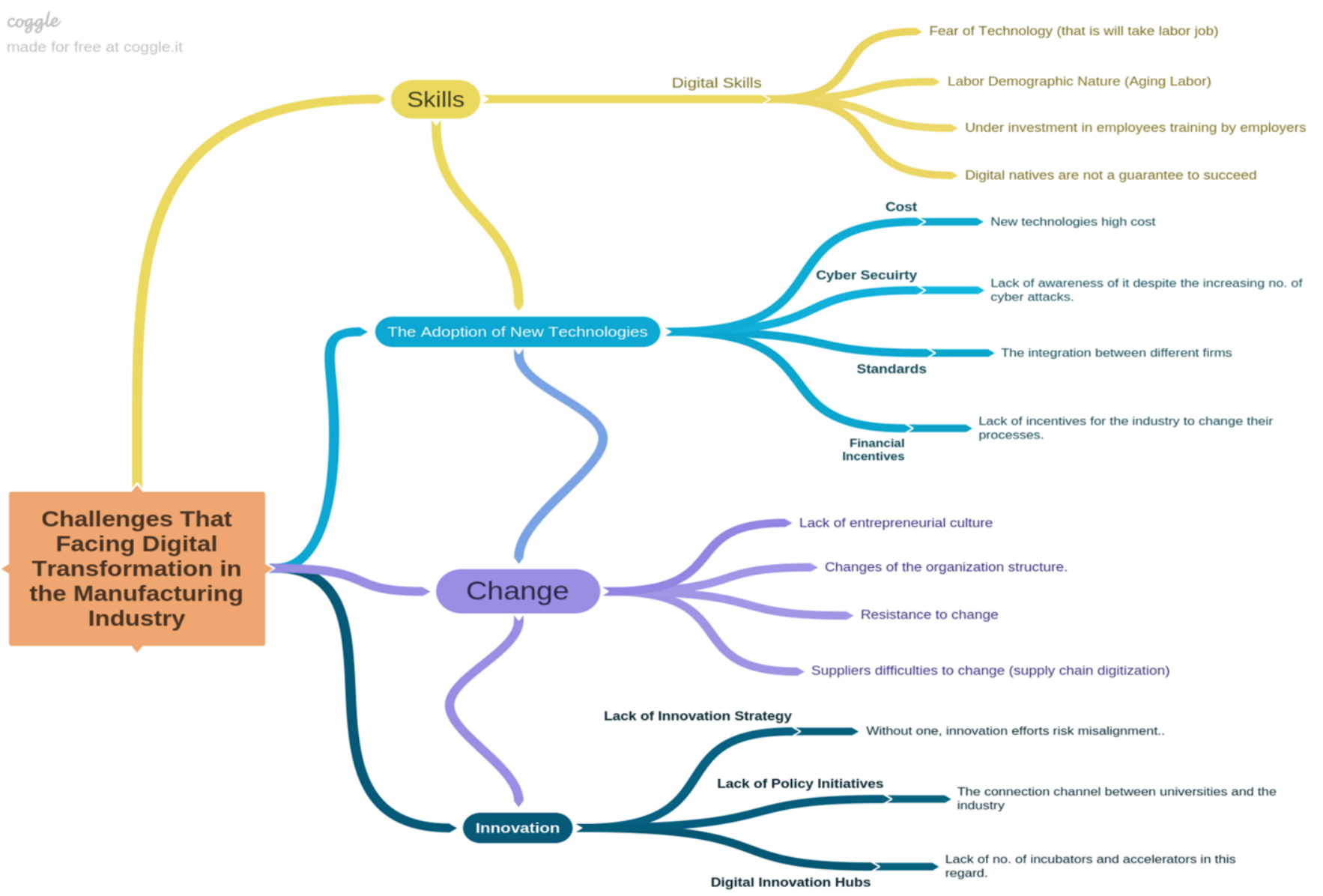

Figure (1) Challenges of DT in the Manufacturing Industry 
Another challenge in this regard is the fear of technology. Labour fear of technology that it will replace their jobs and therefore the resist this transformational place. Nobody wants to lose his/her position in favour of technology or a robot replace his/her career. This mindset needs to be changed ${ }^{8}$. Technology will not remove the labour jobs, but it will reshape them, create more opportunities to innovate and make efficient use of these technologies to become more productive, creative, and do their jobs better.

Digital transformation needs a team that can perform multiple tasks quickly and flexibly. Manufacturing organisations still lack the concept of agile teamwork as it requires much training on different skills and different organisational structures ${ }^{9}$.

\subsection{The Adoption of New Technologies}

Adopting new technologies requires a risk-taking culture inside the organisation. This high risk comes from the high initial investment and long-term return. This type of culture called entrepreneurial culture. Manufacturing firms lack awareness of this culture because businesses, in general, are risk-averse. They tend to invest in low-risk projects with a short-term return. This risk aversion is shown in Made Smarter report in 2017, as stated that there is little investment in new technologies in the manufacturing industry, especially in the SMEs.

Cyber Attack as well play a major part in the digital technologies world ${ }^{10}$. With the increasing number of attacks every day, businesses lose a lot of money and efforts to prevent them. The main problem in these types of attacks is that it is evolving, and every day, new threats are being used to harness the business.

The manufacturing industry is one of the most attractive vulnerable sectors in cyberattacks because of the lack of intellectual property rights and the complexity of supply chains $^{11}$. Manufacturers need to increase the awareness of their employees about cybersecurity and how to protect their connected machines. Moreover, to build a robust information system that prevents the leaks of their data. However, carefully monitoring the data prevents the organisation from cyber-attacks and is the most efficient way to measure organisational goals.

Moreover, one of the most significant obstacles that complicate digital technologies' adoption is the absence of usage standards in these technologies. There is no uniform way to identify or use it. This makes the technology be used in different ways and integrates systems complicated between the manufacturer and its supply chain and between the different departments inside the same organisation ${ }^{12}$. This challenge increases significantly in the SMEs that supply large corporations.

\subsection{Change Management Process}

Digital transformation is a combination of disruptive technologies. This makes it very hard to apply and use. Therefore, one of the most complicated challenges in manufacturing firms is the changing of its structure. Changing an organisation's structure is challenging and needs much time and effort to overcome its resistance.

Another challenge is the resistance to change for the existing employees. They do not want anything to move them from their comfort zones. This requires managing the change process and unfreeze the status quo to make the required modifications. This will also require recruiting change agents that believe in the idea of change and help the management convince their employees of the change and improve their work conditions. 
Managing change is not an easy task in a very dynamic business environment in the manufacturing industry ${ }^{13}$. This requires collaborative efforts on all organisation levels. It also involves digitising the whole supply chain to enhance the productivity of the system. This integration, as mentioned earlier, is not an easy task.

The change will not happen for one time only. It is a continuous process that needs to be managed incrementally to achieve the digital transformation process's organisational goals.

\subsection{Innovation Initiatives}

Innovation is a critical element in the success of digital transformation processes inside the manufacturing industry. On the strategic level of the organisation, most firms lack the existence of innovation strategy ${ }^{14}$. On the national level, no sufficient number of innovation initiatives take place in the manufacturing industry.

There are not sufficient programs like incubators or accelerators that work correctly in digitising the manufacturing industry. These kinds of programs give the funding needed to work on these projects and give them the support and mentoring needed for SMEs to complete their digital business transformation. In addition to that, the initiatives that already existed is confusing and overlapping with each other ${ }^{8}$.

Moreover, the manufacturing sector lacks collaboration between the firms and the universities and research centres. Few universities work with the industry or have technology transfer units that help to achieve this collaboration successfully.

\section{Conclusions}

Digital transformation faces many challenges in the manufacturing industry, such as the digital skills gap, adoption of new technologies, change management practices, and innovation initiatives. These challenges have different intensities and different perspectives. It could range from the human factor to the strategy factor and how to fit the digital transformation process into its organisational culture. Moreover, this sector needs much support from its macro-environment perspective to achieve effective digital transformation.

More policy initiatives and innovation hubs need to be developed on the national level and align all the efforts to encourage SMEs in the manufacturing industry to begin their digital transformation experience. Success stories need to be shared among manufacturers and training and mentoring programs to achieve digital transformation successfully.

\section{Acknowledgement}

The authors would like to thank the Egyptian Government for funding this research under the Ministry of Higher Education grants program for $\mathrm{PhD}$ students.

\section{References}

[1] Culot G, Nassimbeni G, Orzes G, Sartor M. Behind the definition of Industry 4.0: Analysis and open questions. International Journal of Production Economics. 2020;226:107617. 
[2] Fernández-Rovira C, Álvarez Valdés J, Molleví G, Nicolas-Sans R. The digital transformation of business. Towards the datafication of the relationship with customers. Technological Forecasting and Social Change. 2021;162:120339.

[3] Yu F, Schweisfurth T. Industry 4.0 technology implementation in SMEs - A survey in the Danish-German border region. International Journal of Innovation Studies. 2020;4(3):7684.

[4] Horváth D, Szabó RZ. Driving forces and barriers of Industry 4.0: Do multinational and small and medium-sized companies have equal opportunities? Technological Forecasting and Social Change. 2019;146(May):119-132.

[5] Mihardjo LWW, Sasmoko S, Alamsjah F, Elidjen E. Digital leadership role in developing business model innovation and customer experience orientation in industry 4.0. Management Science Letters. 2019;9(11):1749-1762.

[6] Osterrieder P, Budde L, Friedli T. The smart factory as a key construct of industry 4.0: A systematic literature review. International Journal of Production Economics. 2020;221:107476.

[7] Llopis-Albert C, Rubio F, Valero F. Impact of digital transformation on the automotive industry. Technological Forecasting and Social Change. 2021;162:120343.

[8] Benitez GB, Ayala NF, Frank AG. Industry 4.0 innovation ecosystems: An evolutionary perspective on value cocreation. International Journal of Production Economics. 2020;228:107735.

[9] Bai C, Dallasega P, Orzes G, Sarkis J. Industry 4.0 technologies assessment: A sustainability perspective. International Journal of Production Economics. 2020;229:107776.

[10] Gölzer P, Fritzsche A. Data-driven operations management: organisational implications of the digital transformation in industrial practice. Production Planning and Control. 2017;28(16):1332-1343.

[11] Tolkachev SA, Bykov AA, Morkovkin DE, Borisov OI, Gavrilin A V. Digitalization of manufacturing in Russia, Belarus and the European Union. In: IOP Conference Series: Earth and Environmental Science. Vol. 421. IOP Publishing; 2020. p. 32041.

[12] Gökalp E, Şener U, Eren PE. Development of an assessment model for industry 4.0: Industry 4.0-MM. In: O'Connor R.V. Mas A. RTMADA, editor. Communications in Computer and Information Science. Vol. 770. Springer Verlag; 2017. p. 128-142.

[13] Loonam J, Eaves S, Kumar V, Parry G. Towards digital transformation: Lessons learned from traditional organisations. Strategic Change. 2018;27(2):101-109.

[14] Demirkan H, Spohrer JC, Welser JJ. Digital Innovation and Strategic Transformation. IT Professional. 2016;18(6):14-18. 